\title{
DESENVOLVIMENTO PONDERAL DE BOVINOS MEIO-SANGUE IBAGÉ- HEREFORD NASCIDOS EM DISTINTAS ESTAÇÕES DO ANO
}

\author{
GROWTH RATE OF IBAGÉ X HEREFORD CROSSES BORN IN DIFFERENT \\ SEASONS OF THE YEAR
}

\section{Paulo Cláudio Machado Júnior ${ }^{1}$ Eduardo Salomoni ${ }^{2}$ José Carlos da Silveira Osório $^{3}$}

RESUMO

$O$ objetivo deste trabalho foi avaliar a influência das estações de nascimento (primavera e outono) sobre o desenvolvimento ponderal de bovinos mei-sangue Ibagé-Hereford em condições de campo nativo, no Centro de Pesquisa de Pecuária dos Campos Sulbrasileiros, da Empresa Brasileira de Pesquisa Agropecuária, em Bagé-RS. Utilizaram-se para tal 44 animais nascidos na primavera e 30 provenientes de nascimento outonal, pesados a cada 90 dias a partir do nascimento até a idade de 1080 dias. Os produtos nascidos no outono apresentaram os maiores pesos ao nascimento, 360, 630, 720 e $1080(P<0,01) e$, aos 990 dias de idade $(P<0,05)$, enquanto que os de primavera foram mais pesados nas idades de 180, 540 e $900(P<0,01)$ e, 450 e 810 dias $(P<0,05)$.

Palavras-chave: campo natural, bovinos de corte.

\section{SUMMARY}

The aim of this work was to study the influence of calving seasons (spring and autumn), upon growth rate of Ibagé $x$ Hereford crosses $\left(F_{1}\right)$ under natural pasture grazing conditions, at the Centro de Pesquisa de Pecuária dos Campos Sulbrasileiros, of Empresa Brasileira de Pesquisa Agropecuária, in Bagé, Rio Grande do Sul state, Brazil. Seventy four animals (44 born in spring and 30 in autumn) were used, weighed at 90 days intervals from birth up to the age of 1080 days. The highest body weights were observed for animals born in autumn at birth, 360, 630, 720 and $1080(P<0.01)$ and, at 990 days of age $(P<0.05)$, while the animals born in spring were heavier at the ages of 180, 540 and $900(P<0.01)$ and, 450 and 810 days $(P<0.05)$.

Key words: natural grassland, beef cattle.

\section{INTRODUÇÃO}

A alimentação do rebanho bovino na região sul do Brasil apresenta uma peculiaridade que ressalta sua importância. Deve-se ao fato de que tendo a mesma como base de suporte os campos naturais da região e sendo constituídos basicamente de espécies estivais, ocorre uma deficiência nutricional deste recurso forrageiro no período hibernal (LOBATO, 1985; SALOMONI \& SILVEIRA, 1996). A estacionalidade de produção deste tipo de cobertura vegetal se reflete em considerável perda de peso dos animais que a utilizam durante o período de inverno, verificandose assim a acentuada influência que o ano e a estação de nascimento dos animais possuem sobre o desenvolvimento dos mesmos, conforme PFAN \& MÜLLER (1984) e NOBRE $\boldsymbol{e t}$ al. (1987).

Segundo DUTTO (1973) e SALOMONI \& SILVEIRA (1996), com a utilização do manejo tradicional, onde o terço final de gestação coincide com os meses de pouca disponibilidade forrageira, ocorre um consumo ou ausência de reservas por parte das fêmeas antes do parto. Esta situação reflete-se em influências negativas sobre o desenvolvimento final do feto, além de provocar a tendência de perda de peso das fêmeas imediatamente após o parto, culminando na alteração da produção de leite e desenvolvimento dos terneiros. Quanto a isso, RIBEIRO \& PIMENTA FILHO (1990), SALOMONI et al. (1991) e BARCELLOS \&

\footnotetext{
${ }^{1}$ Engenheiro Agrônomo, aluno do curso de Pós-graduação em Zootecnia, FAEM/UFPel.

${ }^{2}$ Engenheiro Agrônomo, MSc., Pesquisador e Chefe Geral do Centro de Pesquisa de Pecuária dos Campos Sulbrasileiros/EMBRAPA,

CP. 242, 96400-970, Bagé, RS. E-mail: salomoni@ cppsul.embrapa.br. Autor para correspondência.

${ }^{3}$ Médico Veterinário, MSc., Doutor, Professor Titular do Departamento de Zootecnia da FAEM/UFPel.

Recebido para publicação em 18.06.98. Aprovado em 02.09.98
} 
LOBATO (1992) observaram maiores pesos ao nascer em terneiros nascidos no outono, quando comparados aos produtos que nasceram na primavera, os quais mostraram-se mais leves nessa idade.

No período inicial de desenvolvimento dos terneiros, observa-se menor peso nos produtos nascidos no outono em relação aos de primavera. Esse efeito é observado até os 205 dias de idade, e é consequiência da maturação das espécies presentes na pastagem natural e da menor produção de leite das vacas, conforme CARDELLINO \& CARDELLINO (1984), BARCELLOS \& LOBATO (1992) e ROVIRA (1996). Entretanto, aos 365 dias, os animais nascidos no outono apresentam maiores pesos do que os de primavera, devido ao fato de permanecerem o primeiro inverno ao pé da mãe, enquanto que os de primavera já se encontram desmamados neste período (LIMA, 1970; SILVA et al., 1983; ROSA et al., 1987; SALOMONI et al., 1991).

Aos 550 dias de idade, os animais nascidos no outono apresentam menor ganho de peso que os oriundos de primavera, pelo fato de os primeiros terem enfrentado dois invernos em pastagem natural, o que enfatiza claramente a interação entre peso dos animais e variações estacionais na produção forrageira deste tipo de cobertura vegetal (BARCELLOS, 1989).

Em razão dessas diferenças, muitos pecuaristas do Rio Grande do Sul, que se dedicam à cria, têm utilizado essas duas épocas de nascimento (primavera e outono) visando à maior eficiência na produção de terneiros. Desta forma, procurou-se, por meio deste trabalho, fornecer subsídios e acrescentar informações aos produtores de gado de corte a respeito do desenvolvimento ponderal de bovinos nascidos em distintas estações do ano.

\section{MATERIAL E MÉTODOS}

O trabalho experimental foi conduzido no Centro de Pesquisa de Pecuária dos Campos Sulbrasileiros (CPPSul), da Empresa Brasileira de Pesquisa Agropecuária (EMBRAPA), situada na região da Campanha do estado do Rio Grande do Sul no município de Bagé, distando $10 \mathrm{~km}$ da sede deste. O clima da região é mesotérmico do tipo subtropical, apresentando chuvas mensais distribuídas de maneira desuniforme (EMBRAPA, 1980). A precipitação pluviométrica anual é de aproximadamente $1450 \mathrm{~mm}$, com uma variação em torno de $20 \%$ e, quanto às temperaturas, a média anual é de $17,8^{\circ} \mathrm{C}$, sendo as médias do mês mais quente $23,9^{\circ} \mathrm{C}$ (janeiro) e $12,1^{\circ} \mathrm{C}$ no mês mais frio (junho), podendo ocorrer temperaturas extremas.
O campo natural apresenta variação estacional quanto aos aspectos quantitativo $\mathrm{e}$ qualitativo. A maioria das forrageiras existentes são gramíneas de ciclo estival, sendo $40 \%$ da cobertura vegetal composta pela grama "forquilha"(Paspalum notatum Flüg.) e pela grama "tapete"(Axonopus affinis Chase), enquanto as gramíneas de ciclo hibernal de maior ocorrência são as "flexilhas"(Stipa spp.).

As avaliações forrageiras dos potreiros utilizados foram realizadas considerando-se a estação climática do ano como fator primordial. Deste modo, ao fim de cada período de três meses, realizava-se a coleta de 50 amostras ao acaso por potreiro. Com o objetivo de estabelecer as disponibilidades de matéria seca e verde do campo natural, utilizaram-se as médias obtidas ao início e fim de cada estação. $\mathrm{Na}$ determinação dos teores de proteína bruta, pelo método Kjeldahl, conforme PEIXOTO \& MAIER (1993), e digestibilidade in vitro das matérias seca e orgânica, segundo TILLEY \& TERRY (1963), agrupavam-se as mesmas em cinco amostras compostas por 10 subamostras, conservando-se sempre a sequiência proveniente da coleta inicial.

Quanto ao animais experimentais, foram utilizados 74 bovinos meio-sangue Ibagé-Hereford, dos quais 44 nasceram na primavera (de 06 de agosto a 04 de novembro) e 30 no outono (de 07 de fevereiro a 18 de abril). Todos os animais foram desmamados com idade aproximada de 180 dias, em 18 de abril para os animais de primavera e 18 de outubro para os de outono, sendo estas as datas de ajuste para os pesos dos animais na referida idade. As pesagens foram realizadas no CPPSul/ EMBRAPA, a intervalos de 90 dias a partir do nascimento até a idade de 1080 dias sem jejum prévio, tomando-se como referência as datas de 18/01, 18/04, 18/07 e 18/10 para se proceder ao ajuste dos pesos dos animais. Desta forma, considerou-se, para os animais nascidos na primavera, o peso de 18/01 como data padrão de ajuste para as idades de 90, 450 e 810 dias; $18 / 04$ para as idades de 180, 540 e 900 dias; 18/07 para as idades de 270, 630 e 990 dias e, 18/10 para ajustar as idades de 360, 720 e 1080 dias. De modo semelhante, procedeu-se para os animais nascidos no outono, os quais tiveram como ponto de partida a data de 18/07 para as idades de 90, 450 e 810 dias, e assim sucessivamente para o ajuste dos pesos às demais idades pré-estabelecidas.

A lotação utilizada durante o período experimental foi determinada considerando-se $400 \mathrm{~kg}$ de peso vivo como uma unidade animal, sendo a carga animal estipulada de $0,7 \mathrm{UA} /$ ha ajustada com o uso de ovinos, distribuída em dois potreiros com área total de 45 ha, exclusivamente de campo natural. 
O delineamento experimental utilizado foi o completamente casualizado com número desigual de repetições para cada tratamento, e os pesos ajustados para as idades pré-estabelecidas, bem como o ganho de peso a cada 180 dias, foram submetidos à análise de variância, utilizando-se o programa de análises estatísticas SAS (1982).

\section{RESULTADOS E DISCUSSÃO}

Com base na tabela 1 , percebe-se os pesos ajustados que diferiram entre si de forma significativa, conforme a estação de nascimento. A variação dos pesos a diferentes idades, de acordo com o tratamento, é reflexo direto da estacionalidade de produção do campo nativo onde os ciclos de maior ou menor produção forrageira coincidem com fases diferenciadas na vida dos animais, de acordo com a época de nascimento dos mesmos.

Os resultados evidenciam superioridade no peso médio ao nascer de $3,6 \mathrm{~kg}(11,4 \%)$ para os produtos de outono em relação aos provenientes de nascimento primaveril, devido ao melhor ambiente pré-natal que a estação de outono proporciona, uma vez que o final da gestação ocorre no período de pasto abundante. Por outro lado, para os partos de primavera, os ventres não dispõem de alimentos em quantidade e qualidade suficientes, que possibilitem o crescimento fetal pleno no terço final de gestação, produzindo assim terneiros mais leves. Resultados semelhantes foram obtidos por SILVA et al. (1983), BARCELLOS (1989), SALOMONI et al. (1991) e SALOMONI \& SILVEIRA (1996).

Tabela 1 - Peso médio (kg) dos animais ao nascerem e ajustado para as demais idades (a cada 90 dias), por estação de nascimento.

\begin{tabular}{ccc}
\hline & \multicolumn{2}{c}{ Estação de nascimento } \\
\cline { 2 - 3 } Idade (dias) & Primavera & Outono \\
\hline & & \\
Nascimento & $31,5^{\mathrm{B}}$ & $35,1^{\mathrm{A}}$ \\
90 & $81,4^{\mathrm{a}}$ & $79,5^{\mathrm{a}}$ \\
180 & $134,2^{\mathrm{A}}$ & $108,2^{\mathrm{B}}$ \\
270 & $144,6^{\mathrm{a}}$ & $153,2^{\mathrm{a}}$ \\
360 & $156,8^{\mathrm{B}}$ & $192,5^{\mathrm{A}}$ \\
450 & $211,4^{\mathrm{a}}$ & $196,3^{\mathrm{b}}$ \\
540 & $256,2^{\mathrm{A}}$ & $215,3^{\mathrm{B}}$ \\
630 & $255,6^{\mathrm{B}}$ & $275,5^{\mathrm{A}}$ \\
720 & $273,1^{\mathrm{B}}$ & $317,0^{\mathrm{A}}$ \\
810 & $327,5^{\mathrm{a}}$ & $303,7^{\mathrm{b}}$ \\
900 & $368,8^{\mathrm{A}}$ & $323,3^{\mathrm{B}}$ \\
990 & $358,5^{\mathrm{b}}$ & $381,1^{\mathrm{a}}$ \\
1080 & $370,8^{\mathrm{B}}$ & $418,2^{\mathrm{A}}$ \\
\hline
\end{tabular}

Médias acompanhadas de letras minúsculas distintas na mesma linha diferem estatisticamente $(\mathrm{P}<0,05)$ e as acompanhadas de letras maiúsculas distintas $(\mathrm{P}<0,01)$. As médias acompanhadas de letras minúsculas iguais na mesma linha não diferem estatisticamente $(\mathrm{P}>0,05)$.
Já aos 90 dias de idade, não houve efeito significativo da estação de nascimento dos terneiros sobre os seus pesos ajustados, provavelmente devido à melhor condição forrageira do campo nativo disponível aos ventres de parto primaveril, após o nascimento dos terneiros (verão), em relação àquela encontrada pelas fêmeas paridas no outono. Isso pode ter ocasionado um efeito positivo sobre sua produção de leite e, conseqüentemente, sobre o ganho de peso de suas crias, além de que, cabe ressaltar a possível piora na condição corporal destas fêmeas ao deslocarem reservas para fazer frente à produção de leite neste período inicial. Assim, os produtos de primavera, apesar de terem nascidos mais leves, foram capazes de apresentar um melhor desempenho até 90 dias de idade em relação àqueles nascidos no outono. Entretanto, a variável produção de leite não foi aferida no presente trabalho, dificultando assim uma melhor compreensão deste resultado.

Aos 180 dias (desmame), os produtos de primavera encontraram-se significativamente mais pesados que os de outono, fruto do maior ganho de peso (tabela 2) obtido pelo primeiro grupo no período de 0-180 dias em relação aos animais de nascimento outonal, semelhante aos resultados apresentados por BARCELLOS (1989), RIBEIRO \& PIMENTA FILHO (1990) e SALOMONI \& SILVEIRA (1996). Isso é consequiência da maior disponibilidade alimentar do campo nativo no período de verão, quando os terneiros de primavera estão se tornando ruminantes e têm sua alimentação, em sua maior parte, dependente dessa produção forrageira. Situação inversa é enfrentada pelos animais nascidos no outono que têm nesse período, início de ruminação, pastos de inverno à disposição, conforme SILVEIRA (1995) e ROVIRA (1996).

Quando os animais atingiram a idade de um ano (360 dias), os produtos de outono superaram, em peso, os de primavera, visto que, após o desmame, o primeiro grupo teve ao seu dispor maior

\begin{tabular}{ccc}
$\begin{array}{r}\text { Tabela } 2 \\
\text { - Ganho médio diário dos terneiros }(\mathrm{kg}) \text { a partir do } \\
\text { nascimento, a intervalos de } 180 \text { dias, por estação } \\
\text { de nascimento. }\end{array}$ \\
\cline { 2 - 2 } Intervalo (dias) & \multicolumn{2}{c}{ Estação de nascimento } \\
\hline & & Outono \\
$0-180$ & $0,570^{\mathrm{A}}$ & $0,406^{\mathrm{B}}$ \\
$180-360$ & $0,126^{\mathrm{B}}$ & $0,468^{\mathrm{A}}$ \\
$360-540$ & $0,552^{\mathrm{A}}$ & $0,127^{\mathrm{B}}$ \\
$540-720$ & $0,094^{\mathrm{B}}$ & $0,565^{\mathrm{A}}$ \\
$720-900$ & $0,531^{\mathrm{A}}$ & $0,035^{\mathrm{B}}$ \\
$900-1080$ & $0,011^{\mathrm{B}}$ & $0,564^{\mathrm{A}}$ \\
\hline
\end{tabular}

Médias acompanhadas de letras maiúsculas distintas na mesma linha diferem estatisticamente $(\mathrm{P}<0,01)$. 
quantidade e melhor qualidade de forragem (campo nativo de primavera e verão) para suprir suas necessidades, proporcionando assim ganho de peso significativamente superior para estes animais no período de 180-360 dias, o que ocorreu de forma inversa para os produtos de primavera. A situação inverte-se novamente aos 540 dias de idade, onde os bovinos provenientes da primavera superaram os nascidos no outono a esta idade, fruto da diferença significativa entre os tratamentos para o ganho de peso dos animais no período de 360-540 dias. Resultados semelhantes para esta idade foram abordados por OLIVEIRA \& LÔBO (1992) e SALOMONI \& SILVEIRA (1996), os quais justificam o fato, afirmando que os animais nascidos na primavera têm ao seu dispor, na fase analisada, um campo nativo em fase de crescimento e com bom valor nutritivo (verão) possibilitando maiores ganhos de peso em comparação aos bovinos oriundos do outono, os quais alcançaram 540 dias de idade após um período recente de carência alimentar (inverno), além de que estes, nesta idade, já enfrentaram dois invernos em campo nativo, frente a um apenas, nas mesmas condições, transposto pelo grupo de nascimento primaveril.

Pela análise da tabela 1 , percebe-se que a estação de nascimento influenciou significativamente $(\mathrm{P}<0,01)$ o peso ajustado dos animais para a idade de 720 dias, expresso pelo maior valor apresentado neste momento para os animais que nasceram no outono. Novamente a justificativa para este resultado encontra-se no ganho de peso (Tabela 2) dos animais, onde, no período de 540-720 dias, este foi significativamente superior para os bovinos de outono em relação àquele apresentado pelos animais nascidos na primavera. Segundo SALOMONI et al. (1991) e SILVEIRA (1995), este fato deve-se à melhor condição alimentar do campo nativo à disposição dos produtos de outono durante o período compreendido entre os 18 e 24 meses (sobreano), não se revelando assim tão evidente a troca de dentes em seu desenvolvimento, oposto ocorrendo para os animais de primavera que terão a crise dentária no forte do inverno.

Novas inversões no peso ajustado ocorreram nas idades de 900 e 1080 dias, sendo que na primeira, os bovinos provenientes de nascimento primaveril superaram em peso os animais de outono (tabela 1), posteriormente (aos 1080 dias), os produtos nascidos na estação outonal apresentaram peso vivo significativamente superior $(\mathrm{P}<0,01)$ em relação aos da primaveril. Essa diferença de peso entre os tratamentos, em ambos os momentos, é fruto das variações estacionais de produção forrageira do campo nativo, o que provoca uma inversão no peso vivo a cada seis meses entre animais nascidos na primavera e no outono (OLIVEIRA \& LÔBO, 1992). Essta justificativa torna-se palpável ao observar-se a Tabela 2, onde é nítida a inversão no ganho de peso entre os tratamentos nos períodos de 720 900 e 900-1080 dias.

Uma análise global dos resultados permite verificar com clareza o efeito da estacionalidade de produção do campo nativo sobre o desenvolvimento dos animais nascidos em diferentes épocas do ano e que utilizam este tipo de cobertura vegetal sob a forma de pastejo. Há uma clara alternância na detenção dos maiores pesos entre os terneiros nascidos na primavera e os nascidos no outono, a cada seis meses, fruto da variação na qualidade e quantidade de forragem disponível aos animais conforme a estação do ano. Cabe destacar também que nas idades de 12, 24 e 36 meses, quando todos os animais sofreram os efeitos oriundos das variações climáticas provocadas pelas quatro estações do ano, os bovinos nascidos no outono apresentam melhor desempenho ponderal expresso pelas suas maiores médias de peso comparadas as dos de primavera, além de que, com o aumento de idade, a diferença em peso daqueles de outono é incrementada em relação aos de primavera, sendo esta de $35,7 \mathrm{~kg}$ (aos 12 meses), 43,9kg (aos 24 meses) e 47,4kg (aos 36 meses).

\section{CONCLUSÕES}

A estação de nascimento de outono possibilita pesos mais elevados em terneiros ao nascimento, a um, dois e três anos de idade, do que a de primavera em condições exclusivas de campo nativo; embora o nascimento primaveril permita desmamar (aos 180 dias) terneiros mais pesados.

\section{REFERÊNCIAS BIBLIOGRÁFICAS}

BARCELLOS, J. O. J. Efeitos da estação de parição no desempenho reprodutivo de novilhas Hereford e suas cruzas e no desenvolvimento de suas progênies. Porto Alegre - RS. 278 p. Tese (Mestrado em Zootecnia) - Curso de Pós-graduação em Zootecnia, Universidade Federal do Rio Grande do Sul, 1989.

BARCELlOS, J.O.J., LOBATO, J.F.P. Efeitos da época de nascimento no desenvolvimento de bezerros Hereford e suas cruzas. I. Peso ao nascer e ganho médio diário pré-desmama. Revista da Sociedade Brasileira de Zootecnia, Viçosa, v. 21, n.1, p.137-149, 1992.

CARDELLINO, M.G.V. de, CARDELLINO, R.A. Efeitos ambientais sobre peso, ganho de peso e conformação à desmama em bovinos Hereford no Rio Grande do Sul. Revista da Sociedade Brasileira de Zootecnia, Viçosa, v. 13, n. 4, p. 547$556,1984$.

DUTTO, L. Manejo fisiologico del ganado de cria: obtención del $95 \%$ de procreos. Montevideo: Hemisferio Sur, 1973. 111

Ciência Rural, v. 29, n. 2, 1999. 
EMBRAPA. Relatório Técnico Anual da UEPAE. Bagé: EMBRAPA/UEPAE, 1980. 121 p.

LIMA, F.P. Observação sobre o crescimento de bezerros de corte sob duas modalidades de manejo (nota prévia). In: REUNIÃO ANUAL DA SOCIEDADE BRASILEIRA DE ZOOTECNIA, 7, 1970, Piracicaba. Anais... Piracicaba: Sociedade Brasileira de Zootecnia, 1970. p. 70-74.

LOBATO, J.F.P. Gado de cria: tópicos. Porto Alegre: Adubos Trevo S.A., 1985. 32 p.

NOBRE, P.R.C., EUCLIDES FILHO, K., ROSA, A. N. Repetibilidade e herdabilidade do peso ao nascer de gado Nelore por estação de nascimento. Revista da Sociedade Brasileira de Zootecnia, Viçosa, v. 16, n. 4, p. 370-376, 1987.

OLIVEIRA, J.A. de, LÔBO, R.B. Fatores ambientes e genéticos relacionados com o peso aos dezoito meses e ganho diário em bovinos Guzerá. Revista da Sociedade Brasileira de Zootecnia, Viçosa, v. 21, n. 4, p. 629-636, 1992.

PEIXOTO, R.R., MAIER, J.C. Nutrição e alimentação animal. 2 ed. Pelotas: Universitária, 1993. 169 p.

PFAN, L.A., MÜLLER, L. Desempenho produtivo de novilhos da raça Charolesa e azebuados alimentados com três tipos de suplementação no período hibernal. Revista da Sociedade Brasileira de Zootecnia, Viçosa, v. 13, n. 2, p. 201-210, 1984.

RIBEIRO, M.N., PIMENTA FILHO, E.C. Fatores ambientais que afetam os pesos de bezerros Nelore até o desmame. In: REUNIÃO ANUAL DA SOCIEDADE BRASILEIRA DE ZOOTECNIA, 27, 1990, Campinas. Anais... Campinas: Sociedade Brasileira de Zootecnia, 1990. p. 465.

ROSA, A.N., NOBRE, P.R.C., EUCLIDES FILHO, K. Desenvolvimento ponderal de animais da raça Nelore variedade mo- cha: parâmetros genéticos e de ambiente. In: REUNIÃO ANUAL DA SOCIEDADE BRASILEIRA DE ZOOTECNIA, 24, 1987, Brasília. Anais... Brasília: Sociedade Brasileira de Zootecnia, 1987. p. 286.

ROVIRA, J. Manejo nutritivo de los rodeos de cría en pastoreo. Montevideo: Hemisferio Sur, 1996. 288 p.

SALOMONI, E., BORBA, E.R., LEAL, J.J.B., et al. Efeito da época de acasalamento no desempenho produtivo de vacas de corte. In: EMBRAPA. Centro Nacional de Pesquisa de Ovinos. Produção de terneiros - Manejo de matrizes. Bagé: EMBRAPA - CNPO/URCAMP, 1991. p. 51-57.

SALOMONI, E., SILVEIRA, C. L. M. da. Acasalamento de outono em bovinos de corte: abrace essa idéia. Guaíba: Agropecuária, 1996. 152 p.

SAS, Raleigh, NC. SAS User's Guide: Statistics. Cary, NC, 1982.584 p.

SILVA, L.O.C. da, MILAGRES, J.C., SILVA, M.A., et al. Efeitos de fatores de meio sobre pesos de animais Nelore a várias idades. Revista da Sociedade Brasileira de Zootecnia, Viçosa, v. 12 , n. 2, p. 323-336, 1983.

SILVEIRA, C.L.M. da. Influência da estação de parição sobre o comportamento produtivo em vacas de corte. Pelotas RS. 118 p. Tese (Mestrado em Zootecnia) - Curso de Pósgraduação em Zootecnia, Universidade Federal de Pelotas, 1995.

TILLEY, J.M.A., TERRY, R.A. A two-stage technique for the in vitro digestion of forage crops. Journal of the British Grassland Society, Berkshire, v. 18, n. 2, p. 104-111, 1963.

Ciência Rural, v. 29, n. 2, 1999. 